\title{
Interethnic Workplace E-mail Communication: An Investigation into Politeness Strategies
}

\author{
Mohammad Awad AlAfnan \\ English Language Department, BMIC, Malaysia \\ mohammad_alafnan@bmic.com.my
}

\begin{abstract}
The use of email in business communication might be troublesome in the sense that the language of emails is generally theorized as a mixture of spoken and written varieties. This possibility might even increase further among communicators who belong to different ethnic backgrounds as they have different perspectives to communication and expectations of how messages should be structured. Research shows that politeness strategies used by native speakers might be viewed in an unpleasant way by nonnative speakers and vice versa; however, very little research has been done pertaining politeness strategies used by different types of nonnative speakers. Drawing upon Brawn and Levinson's (1987) politeness theory, this study investigates politeness strategies used in Malaysian workplace emails.
\end{abstract}

Index Terms - Politeness strategies, Bold on-record, Positive politeness, Negative politeness

\section{Introduction}

Since the early days of email, researchers realized that this new medium of communication has new conventions that do not fully belong to spoken or written varieties of language. Shapiro and Anderson (1985, p. 10), for example, pointed out that email is "a fundamentally new medium with significantly new characteristics that cannot be treated with the old rules alone". Researchers realized that this new medium of communication have affected cultural value, workplace environment, and language use. This is particularly tormenting, especially, in communications among employees who belong to different cultures and ethnic backgrounds. Previous research on politeness in workplace emails either focused on the strategies used by native speakers or compared them with those used by non-natives, however, very little work has been done concerning politeness strategies used by different types of non-native speakers using the lingua franca English (Swangboonsatic, 2006). Having said that, this study investigates politeness strategies used in emails that are exchanged in a private Malaysian educational institute where the employees belong to different ethnic backgrounds.

\section{Methods}

As this study examines politeness strategies used in the content moves of the emails, the researcher draws on Brown and Levinson's (1987) politeness theory. Brown and Levinson (1987) stated that people are driven by the desire to be approved by others (which they called positive face), but at the same time, be independent (which they called negative face). They suggested five politeness strategies that can be used by communicators in response to Face Threatening Acts (FTA), namely, the on-record politeness strategy, which is the most direct strategy, positive politeness strategies, which appeals to hearer's desire to make the issue more acceptable and convincing, negative politeness strategy, in which the speaker minimizes any imposition on the hearer, and take in considerations hearers' willingness not to be imposed or pushed, off-record strategy, in which the speaker presents his statement or question in an ambiguous or indirect way and the say nothing strategy, in which the speaker chooses to ignore or not to make any requests.

The used strategy depends on the weightiness or the social situation of the face threatening acts. Brown and Levinson (1987, p. 77) argued that speakers usually take in consideration three factors to assess weightiness that are the degree of imposition, the power of the hearer over the speaker and the social distance between the communicators.

Even though politeness theory was presented to study face-to-face interactions, it was successfully used in investigating asynchronous communication (Akar, 1998; Grindsted, 1997; Maier, 1992; Sheer, 2000).

\section{Results and Findings}

The researcher identified 1168 politeness moves in the content of the 522 email messages. As the members of the different ethnic background participating in the study wrote different numbers of messages, the number of politeness moves also varied. Examining these moves shows that they were bald on-record, positive politeness and negative politeness strategies. Interestingly, the off-record politeness strategy was not used in the emails.

\subsection{Direct Politeness Strategy (Bald on-record)}

The bald on-record strategy is "whenever $\mathrm{S}$ wants to do

the FTA with maximum efficiency more than he wants to satisfy H's face, even to any degree" (p. 95). However, in task oriented communication, the focus might be drown to the task and "face redness may be felt to be irrelevant". Examining the usage of the bald on-record politeness strategy in the emails shows that this latter point was the main purpose of using the 192 (16 percent) imperative and interrogative bold on-record instances in the emails.

The bold on-record imperative form occurred 171 times in the corpus in an overall frequency of 15 percent of politeness strategies. Imperative sentences appeared in two different forms that are the direct imperative as in 'find attached', and the use of mitigation device in front of the verb as in "please 
revert'. Noticeably, the participants from all the different ethnic backgrounds participating in the study used the imperative form to construct requests. Examining the use of the imperative forms according to the ethnic background of email writers shows that 33 percent of the moves were written by Chinese Malaysians, 31 percent by Indian Malaysians, 19 percent by Malays, 15 percent by British, and one percent by each of the Jordanian lecturer and African students.

Even though the usage of imperative forms is the most efficient way of presenting requests, this form is usually viewed as the most direct and the least polite (Carrell and Konneker, 1981). As such, in order to reduce the imposition in the imperative sentence, Chinese Malaysian respondents used a number of mitigation devices such as 'please' (30 instances), 'please kindly' (18 instances), and 'kindly' (8 instances). According to Treece (1994), the usage of 'kindly' is conventional in business communication as it is formal and polite, whereas the usage of 'please' is less formal and mainly occurs in oral correspondence (Angell and Heslop 1999, p. 56). In the emails, however, it is noticed that the conventional practice is the usage of 'please' as it appeared in 30 out of the 57 instances (53 percent), whereas 'kindly' appeared in 8 instances (14 percent) of the Chinese Malaysian imperative on-record politeness. The use of 'please' was also popular among other ethnic backgrounds as 85 percent of the Malays, 92 percent of Indian Malaysian, 92 percent of the British, and 100 percent of the Jordanian and African respondents started their imperative on-record politeness using this mitigation device. The usage of the double mitigation 'please kindly', which appeared in 18 instances (32 percent), was used by a single respondent, which, as a result, reflects a personal rather than an organizational practice. The main purpose of using the double mitigation device, according to the only user, is to be 'more' polite and motivate the recipient to respond to the request. Linguistically, however, the use of the double mitigation devices can be interpreted as an enforcement and imposition to emotionally thrust the recipient to attend to the presented request.

Examining the effect of hierarchy on the use of the imperative on-record politeness shows that the 171 imperative on-record moves were used by equals (65 instances) subordinates (64 instances) and superiors (42 instances). Malay and British subordinates used this technique more than superiors did, whereas Indian Malaysian superiors used it more than subordinates. The use of this strategy by Chinese Malaysian respondents, however, was among equals. The single case of using the imperative on-record strategy by the Jordanian lecturer and the two used by the African students were used by subordinates as well. This shows that subordinates and equals used this strategy more than superiors, which supports Bishop and Levine's (1999) assumption that the usage of emails between superiors and subordinates reduces status imbalance between the two groups. As example 1 shows, a Malay part-time lecturer requests from the head of professional studies to inform the assistant academic director that she will not be able to teach a given module in the coming semester. In example 2, a British external contact informs the head of studies that a new officer was nominated to be the new contact person with the college. The usage of 'please' in front of the imperative in this example does not carry a request as in other examples, but it directs the attention of the recipient about the latest changes.

Ex 1 (4.32): Please inform Mr VK that i wont be able to teach CS from June onwards.

Ex 2 (3.5): Please note that from today Catherine $H$ will be your...

Ex 3 (3.52): Kindly respond to this email asap.

Ex 4 (1.5): Please kindly e-mail me ASAP the Excel marksheet

Even though the usage of the imperative is the most direct method of presenting requests and directing the attention of recipients to attributed issues, as explained earlier, the actual use of this strategy in internal and external emails by subordinates shows that it is 'polite enough', especially if proceeded by a mitigation device such as 'please' or 'kindly'

( $\mathrm{Ng}, 2003)$. In example 3, the writer, who is an Indian Malaysian superior, requests from the recipient to respond to the email as soon as possible.

Examining the influence of social distance on the use of imperative politeness shows that 106 out of the 171 imperative on-record politeness moves (62 percent) were sent to close workmates, while the remaining 38 percent were sent to distant workmates. It is obvious that Malay, Chinese Malaysian, Jordanian, and African respondents mainly used the imperative form when communicating to close workmates, while Indian Malaysians used this strategy when communicating to close and distant workmates alike. Given that all the British respondents are based in the UK, all Malaysian informants categorized them as distant workmates, except a single British contact who was based in Malaysia for a short time in the past. As such, it is clear that social distance played a more significant role than hierarchy in using the direct on-record politeness strategy. It is noticed that Malaysian respondents in general, and Malay and Chinese Malaysian in particular, used this technique when communicating to close workmates more than using it when communicating to distant workmates.

The usage of the interrogative direct on record politeness strategy, in fact, is the least frequent politeness strategy in the corpus. It occurred 21 times in an overall frequency of eleven percent of the bald on-record politeness strategy and 1.6 percent of the overall politeness strategies in the emails. It is noticed that interlocutors used three different forms of interrogative sentences to present their requests that are the 'yes/ no questions', 'Wh-questions', and 'any news on'.

Generally, interrogative on-record politeness strategy is rated less direct than the imperative on record; however, the actual use of these two on record politeness strategies in the emails shows that the usage of the imperative, interestingly, is less direct than the usage of interrogative. The conventional practice of using the imperative form in the emails, as explained in previous section, was affiliated with a mitigation 
device (98 percent), which downplayed the effect of the imperative and helped the employees to view it as a polite request. The usage of the interrogative form, however, was mainly presented directly stating the request without using mitigation devices. The overall frequency of using this strategy shows that it was not a very popular practice among the interlocutors and it cannot be considered as a conventional method of requesting in the workplace. The 21 occurrences of the interrogative on-record politeness strategy were mainly used by Indian Malaysian respondents (57 percent). The remaining 9 instances were used by Malay (4 instances), Chinese Malaysians (2 instances), African (2 instances), and Jordanian and British respondents (a single time each).

\subsection{Positive Politeness Strategies}

The overwhelming majority of positive politeness

strategies were used by Malaysian respondents who used around 82 percent of the occurrences. The Indian Malaysians used it in 154 instances, the Malay respondents in 117 instances, the Chinese Malaysian in 50 instances, whereas the British and the Jordanian respondents in 6 instances.

The use of the positive politeness strategies might be distinguished to two main categories that are the 'indispensable" and "social accelerators" strategies.

Indispensable strategies refer to the strategies are irreplaceable in the workplace that without using them a delay and an unfinished business will arise. These strategies include offer and promise and give/ ask for reasons. The social accelerator strategies, however, refer to the strategies that are used to build or maintain a relationship between the sender and the recipient of the email. They are used to come close to the recipient in order to show intimateness in the relationship. These strategies include the nine remaining strategies. The use of the two indispensable positive politeness strategies could be redressive, as explained by Brown and Levinson (1987), but their presence is unavoidable for a smooth and a straightforward exchange of information in the institute (see example $5 \& 6$ ).

Ex 5 (4.29): The ABE student welcome packs will be dispatched to your college

Ex 6 (3.23): We have planned this Conference so that it incorporates a number of different areas that should prove valuable to members of staff

As example 5 shows, the writer promises the recipient that the welcome packs 'will be dispatched to the college'. In fact, the recipient of this email wrote a number of emails earlier asking about the welcome packs, but there were a number of problems regarding the registration of the students. In this email, the English partner promises to dispatch the welcome packs to the institute. In example 6 the writer gives reasons about the purpose of planning the given conference to clarify the expectations to the recipients. This 'give reasons' positive politeness strategy was preceded by the initial move informing about the conference and was followed by a move explaining that for the 'given reasons', the management expects at least a single participant form each center to participate in the conference. As such, the use of these two positive politeness strategies is vital in the workplace to conduct the organizational tasks, which explains their high frequency in the corpus. The use of these two positive politeness strategies was common among all the respondents representing the different ethnic backgrounds in an overall frequency of 48 percent of the positive politeness strategies used in the emails.

'Social accelerator' positive politeness strategies, however, were mainly used to maintain a friendly workplace environment. Unlike the use of the indispensable strategies that were popular among all the respondents from the different ethnic backgrounds, the use of these nine strategies varied among the respondents, which shows that the respondents from the different ethnic backgrounds have different strategies to maintain a friendly and intimate relationship with the recipient. In example 7 , the writer wrote the email to an external partners requesting feedback regarding an issue. In order to stimulate a quicker response, the writer assumes that the recipient will respond to the email 'shortly'. The same technique was used in example 8 , in which the writer, who is the head of students' counseling unit, explains an issue regarding one of the students. As she cannot help the student solve the problem, she wrote the email 'hoping' that the recipient will help her regarding the matter.

Ex 7 (5.25): I look forward to hearing from you shortly. Ex 8 (2.44): i hope that $A B E$ will assist me in this matter.

Examining the effect of hierarchy shows that 35 percent of the positive politeness strategies were used by superiors, 35 percent by equals and 30 percent by subordinates, which supports Brown and Levinson's (1987, p.250) assumption that positive politeness strategies are mainly used when the recipient has no or low power over the sender. Examining the effect of social distance shows that 58 percent of the strategies were exchanged between close workmates, whereas the remaining 42 percent between distant workmates, which also supports Brown and Levinson's (1987) assumptions that positive politeness strategies are mainly used when the writer and the recipient have "low D" relations (p.250). However, it is noticed that some positive politeness strategies were more popular among distant workmates such as 'be optimistic' and 'show understanding and cooperation'. Malay respondents, for example, used 'be optimistic' positive politeness strategy 37 times, all of which in emails sent to distant workmates. In fact, 81 out of the 117 positive politeness strategies (69 percent) used by Malay respondents were used in emails that were sent to distant workmates, which shows that the use of these strategies by the Malay respondents functioned as social accelerators to come closer to the distant workmates. Chinese Malaysian respondents, however, used all the 112 positive politeness strategies in emails that are sent to close workmates, which shows that they used these strategies to maintain a friendly workplace environment.

\subsection{Negative Politeness Strategy}

Negative politeness is the most popular politeness strategy used in the emails, as the overall use of this strategy equals 44 
percent (506 instances). Examining the actual use of the negative politeness strategies shows that some strategies were more popular than others. 'Give deference' was the most common negative politeness strategy, As example 9 shows, the student used 'Sir' in the middle of the request to give deference to the lecturer. This practice, in fact, was very popular by the students as they, out of respect, did not want to use the actual name of the lecturer or refer to him using the pronoun 'you'. However, if the use of 'you' was unavoidable, they used 'sir' after the second person pronoun as it is clear in example 9. In addition to raising the recipient, some of the students used humbling the self strategy, however, in the preclosing move of the email using 'your student' The use of 'your student' in example 9, however, does not reflect deference, as it is used to identify the self rather than humbling the self. Another interesting point in example 9 is the mixture of the positive and negative politeness strategies in a single sentence. As it is clear in example 9, the student used the 'give deference' negative politeness strategy in the middle of the 'be optimistic' positive politeness strategy. That is, the student expressed his need, using the 'be optimistic' positive politeness strategy, expecting the lecturer to fulfill his want or need, however, in a very polite way by giving deference to the lecturer using the negative politeness strategy. The mixing of the positive and the negative politeness strategies, in fact, intended to make the request, which is a face-threatening act, friendlier and less imposing. In addition to the students, it is noticed that Malay respondents used this strategy in 16 instances. Malay respondents mainly used this strategy when communicating to superiors, particularly with the executive director of the institute. As example 10 shows, the head of students' counseling unit wrote an email to the executive director expressing a lecturer's 'want' to have an appointment with him. As it is clear in the example, the writer did not want to use the second person pronoun 'you' as a matter of respect. Alternatively, she replaced it by 'Sir' to give deference to the director, who is actually the co-owner of the institute.

Ex 9 (7.10): This is Wxxx Yxxx, your student, I need to see you Sir to talk about something

Ex 10 (2.59): He wants to have an appointment with $\mathrm{Sir}$ on 24/5/2010 (Monday) at 12.00 noon.

Examining the effect of power and social distance on the use of the negative politeness strategies shows that close and distant subordinates used 190 negative politeness strategies (37 percent and equals distant workmates used 149 (29 percent), and superiors and equals close workmates used 167 (33 percent). As such, it is clear that 67 percent of the negative politeness strategies were used by close and distant subordinates and distant superiors and equals, which supports Brown and Levinson's (1987) assumption

\section{Conclusions}

This study has revealed that Chinese and Indian Malaysian respondents, by using more direct on-record and positive politeness, are more concerned about presenting the task in an efficient and friendly way than they are concerned about the recipient's "want of to have his freedom of action unhindered" (Brown and Levinson, 1987, p. 129). The Malay and the Jordanian respondents, however, by using more positive and negative politeness, are more concerned about the recipients' want to be desirable and freedom of action. The

African and British respondents, however, by mainly using the negative strategy, are mainly concerned about having the recipients' freedom of action unhindered. That is, they mainly focused on giving the recipient options rather than imposing on him/her.

This study also revealed that social distance played a more significant role than power imbalance in the actual choice of politeness strategies. This is supported by the fact that most direct politeness strategies were used by close workmates regardless of their organizational position, whereas a great deal of negative politeness strategies were used by distant workmates. This actually means that Malaysians (Malays, Chinese Malaysians, and Indian Malaysians) are more polite to distant workmates than they are to close workmates.

\section{References}

[1] Akar, D. (1998). Patterns and variations in contemporary written business communication in Turkey: A genre study of four companies (Unpublished dissertation). University of Michigan, Ann Arbor.

[2] Angell, D. \& Heslop, B. (1999). The Elements of E-Mail Style. New York, NY: Addison Wesley.

[3] Bishop, L., \& Levine, D. I. (1999). Computer-mediated communication as employee voice: A case study. Industrial and Labor Relations Review, 52(2), 213-233. doi: 10.2307/2525163

[4] Brown, P., Levinson, S. (1987). Politeness: Some universals in language usage. Cambridge, England: Cambridge University Press.

[5] Carrell, P. L., \& Konneker, B. H. (1981). Politeness: Comparing native and non-native judgment. Language Learning, 31(1), 17-30. doi: 10.1111/j.1467-1770.1981.tb01370.x

[6] Grindsted, A. (1997). Joking as a strategy in Spanish and Danish negotiations. In F. Bargiela-Chiappini \& S. Harris (Eds.), The languages of business: An international perspective (pp. 159-182). Edinburgh, Scotland: Edinburgh University Press

[7] Maier, P. (1992). Politeness strategies in business letters by native and non-native English speakers. English for Specific Purposes, 11, 189-205. doi: 10.1016/S0889-4906(05)80009-2

[8] McLuhan, M., \& Fiore, Q. (1968): War and peace in the global village: An inventory of some of the current spastic situations that could be eliminated by more feed forward. New York, NY: Bantam.

[9] Shapiro, N. and Anderson, R. (1985) Toward an Ethics and Etiquette for Electronic Mail. Santa Monica, CA: The Rand Corporation.

[10] Sheer, V. C. (2000). Conflict process in China's international export trading: Impact of the Chinese culture and the trading culture. Intercultural Communication Studies, 9(2), 47-69. Retrieved from http://www.uri.edu/iaics/content/2000v9n2

[11] Swangboonsatic, C. (2006): Text and context in international trade communication: A case study of e-mail: Business communication among professionals in the Asia-Pacific region (Doctoral dissertation, Victoria University of Technology, Melbourne, Australia). Retrieved from http://eprints.vu.edu.au

[12] Treece, M. (1994). Successful Communication for Business and the Professions. Boston, MA: Allyn \& Bacon. 